\title{
FACTORS AFFECTING NIGHT-TIME VISIBILITY OF RETROREFLECTIVE ROAD TRAFFIC SIGNS: A REVIEW
}

\author{
Roxan Saleh $^{1}$, Hasan Fleyeh ${ }^{2}$ \\ ${ }^{1}$ Swedish Transport Adminstration, Röda vägen 1, SE-781 89 Borlänge, Sweden \\ ${ }^{1,2}$ School of Technology and Business Studies, Dalarna University, Borlänge, Sweden
}

Received 26 November 2020; accepted 27 December 2020

\begin{abstract}
Road traffic signs define a visual language that can be interpreted by drivers. They represent the current traffic situation on the road, show danger and difficulties around the drivers, give them warnings, and help them with their navigation by providing useful information that makes driving safe and convenient. The main part of the road traffic sign is the retroreflective material which reflects the light from the vehicle headlights to the driver. Driving during night-time is a challenge, and the rertoreflective material on the sign board helps the drivers to perceive and interpret the information on the road traffic sign properly. The aim of this paper is to study the factors affecting the performance of driving during nighttime and the role the retroreflective material that plays in this regard. The vehicle headlights, ambient conditions, and the type of retroreflection material affect the light reflected from the road traffic signs. It is also found that the retroreflectivity depends on vehicle factors such as headlights colour and angle of illumination. Other factors such as environmental factors and sign factors can also affect the retroreflectivity.
\end{abstract}

Keywords: road traffic sign, retroreflective material, night-time visibility.

\section{Introduction}

Road traffic signs (European Committee for Standardization, 2007) represent one of the most important elements of road safety (Berces et al., 2012). The purpose of road traffic signs can vary from warning the drivers, to giving them information about the road, and guiding them. They simply provide visible rules about the road to the drivers to keep them safe. Good visibility of the road traffic signs makes drivers able to react in a proper way at a proper time and distance while the low visibility increase the rate of accidents and cause a relatively higher risk of material damage, injuries and even death (Šarić et al., 2018). It is therefore important that the road traffic signs must be visible to the drivers.

To increase the visibility of the road traffic signs we must be aware of the factors that affect visibility and control these factors to get the optimal visibility. The visibility of a road traffic sign defines as the ability of the drivers to detect and read the sign and then understand its meaning. The visibility is a measure of the distance at which an object or light can be clearly discerned. The visibility distance is the distance that the driver needs to locate, read, understand, and react according to the information that

\footnotetext{
${ }^{2}$ Corresponding author: hfl@du.se
} 
the road traffic sign gives, as illustrated in Figure1. The visibility distance is divided into detectability distance, which begins when a sign has been detected and legibility distance, which begins when a driver begins to read its content.

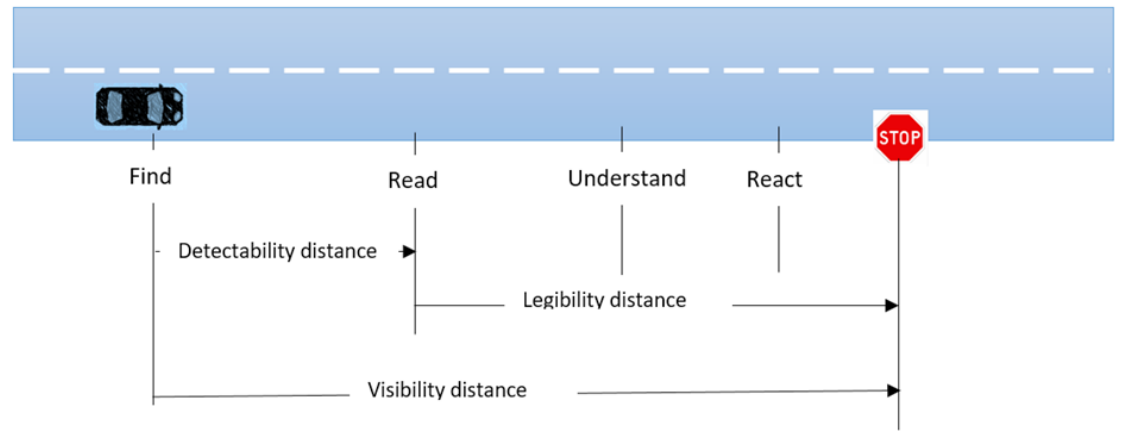

Fig. 1.

Visibility Sequences

Source: Generated by the authors

The visibility of the road traffic sign can be improved by strengthening the interaction between the road traffic sign and the driver. However, this interaction cannot be easily predicted (Garvey et al., 2011) because the ability of a driver to detect and read a road traffic sign is a function of numerous factors such as human, environmental, and design factors which are characterized with complex interrelationships. Furthermore, the design and placement of a road traffic sign has a big effect on the sign visibility. The design of a detectable, legible, and understandable road traffic signs is a big challenge to ensure a safely driving in the road.

At night, the visibility of the signs improves by using retroreflective sheeting materials on the face of the road traffic signs. Almost all the road traffic signs in use today are supplied with retroreflective materials with some level of retroreflectivity. The retroreflective sheeting material on the road traffic signs helps in increasing visibility by reflecting the incident light (from headlights of the vehicle) back towards the drivers' eyes. The reflected light makes the road traffic sign more visible depending on the amount of light falling onto the surface of the road traffic sign.

The development of retroreflective sheeting materials dates back to the 1930s (Berces et al., 2012) and since 1956 the visibility of the road traffic signs at night has been studied (Allen et al., 1956). The retroreflective sheeting was improved and was in use since 1970. Almost all the road traffic signs that in use today are retroreflective and the task of choosing between different types of retroreflective sheeting to get a detectable and legible road traffic signs is a challenge for the designers.

To be able to choose the adequate retroreflective sheeting material one must be aware about what factors that can affect the performance of the retroreflective sheeting materials. Many researchers have investigated the effects of different factors, 
such as retroreflectivity, human factors or weather conditions, on the visibility. The environmental conditions around road traffic signs have a big influence on the sign's visibility. Therefore, the effects of ambient conditions (day- and night-time lighting conditions) on the visibility have been investigated in so many fields and laboratory studies. The results of an eye tracking study that was carried out under good light conditions (during the day) and low light conditions (at night) showed that there is a significant reduction in the visibility of road traffic signs during driving at night (Madleňák et al., 2018).

Sign visibility research studies focused on two main areas: sign detection and sign legibility and therefore this review focused on detectability and legibility. Those two areas are interdependent because a sign must be found before reading it and there is no need to detect a sign that cannot be read from the road (Garvey et al., 2011).

The first aim of this paper is to test the hypotheses that night-time visibility of the road traffic signs depends on the retroreflectivity and the luminance of the retroreflective road traffic signs. The results from this paper allow us to prove the importance of using the retroreflective sign sheeting to improve night-time visibility and allow the drivers to detect and read the road signs in a minimum distance. Moreover, this paper also contributes by gathering the existing knowledge from reports and articles about the effect of using retroreflective material sheeting in increase night-time visibility of the road traffic signs.

The second aim was to increase the understanding of the role of different factors in affecting the visibility and retroreflectivity of the road traffic signs. This paper gives an overview about the factors affecting the night-time visibility of retroreflective road traffic signs and investigates the connection between those factors and the retroreflectivity. In the main while, attempts to illustrate the gab in the literatures about the factors affecting the retroreflectivety and the luminance of the retroreflective road traffic signs.

This review is important for researchers studying the retroreflectivity because it is printing a map for the recent papers on the factors affecting the visibility of the road traffic signs and in the same time gives a description of the lack in the present studies. An important contribution of this paper is in demonstrating what factors affect visibility and retroreflectivity and in the other hand, what factors not covered by research and at the same time gives recommendations for future studies.

Overall, the present paper makes significant contributions in understanding interaction between night-time visibility and retroreflectivity of the road traffic signs. The results can provide support for road authorities when it comes to the importance of using retroreflective sheeting materials to improve the visibility of the road traffic signs.

This paper includes three main parts:

- The first part of the study (Section 3) summarizes the published research studies related to the factors affecting night-time visibility of the retroreflected road traffic signs;

- Because this study is directed towards the retroreflective road traffic signs, a separate section (Section 4) about the relationship between retroreflectivity, 
luminance and other factors were included in the study;

- The third part includes a discussion (Section 5). In the discussion, factors affecting visibility categorized into groups according to several different topics;

- Finally, in the conclusion, research gap and the contribution of this study is presented.

\section{Method}

The retroreflective sheeting materials were used in the road traffic signs since 1947 and have been in focus of studies since 1960s. A big development achieved in the visibility performance of these materials in the latest years because of the developing in manufacturing procedures and using new technologies. There are huge amount of papers studying retroreflectivity of road traffic signs using different types of retroreflective sheeting material but this paper reviews only on the materials that in use and manufacture today, thus this paper focuses on the studies that were achieved since 2010. In some parts, references were made to the reviews done before 2010 to get some overview about the previous works associated to the road traffic signs and visibility at general.

The published research studies related to the factors affecting night time visibility of the retroreflected road traffic signs included in this paper but the degree of effect (increasing or decreasing) of each factor on the visibility, which resulted from the literature, was not included in this study. Only the factors affecting the night-time visibility are mentioned in this study.
The literature was searched using Google Scholar that includes journal and conference papers, theses and dissertations, academic books, pre-prints, abstracts, technical reports, and other scholarly literature from all broad areas of research.

\section{Night-time Visibility}

The visibility of the road traffic signs at night has been studied since 1956 (Allen et al., 1956) and the factors affecting visibility was investigated since that time. Most of the studies focused on the font and colour, age and type of retroreflective sheeting as changeable factors in these studies. Since 1977 many studies pointed that the visibility of the road traffic signs can be affected by the age of the drivers (Sivak et al., 1979).

Most of the studies on the retroreflective sheeting were designed to improve the visibility in a local road and investigate the effect of only one or two factors together. For example, in the USA, the choice of a proper font (type and size) was studied and the effect of font type and size in improving the visibility investigated (Carlson, 2001), (Chrysler et al., 2002).

Sign visibility is an imprecise term in that it encompasses both sign detectability and sign legibility (Garvey et al., 2011). Results from several studies, which describe how different factors can affect visibility in terms of conspicuity and legibility, are summarized in the following subsections.

\subsection{Detectability}

Detectability, which is defined as the ability to read and process the information on the 
sign, is directly related to the ability to detect and find the sign (Garvey et al., 2011). In general, the existing literature were not studied the detectability as much as the legibility.

The location of the sign relative to the rest of the road equipment can enhance the detectability of that sign and make it compete with other signs and objects on the road (Lundkvist, 2012), (Garvey et al., 2011). The degree of visual complexity where a sign is located has also impact on how easily it can be detected (Carlson et al., 2017), (Garvey et al., 2011), (Bullough, 2017). Furthermore, adding a border around the sign, often enhances its detectability (Bullough, 2017).

Other factors that enhance the detectability include size, colour, and shape of the sign (Bullough, 2017), (Lundkvist, 2012), (Garvey et al., 2011), (Carlson et al., 2017). For example, increasing the sign's size can enhance the detectability (Garvey et al., 2011).

Table 1

Factors Affecting Detectability

\begin{tabular}{|c|c|}
\hline Factor & Study \\
\hline Location of the sign & (Lundkvist, 2012), (Garvey et al., 2011) \\
\hline Adding border around the sign & $\begin{array}{c}\text { (Bullough, 2017) } \\
\text { (Owens } \text { et al., 2007), (Carlson } \text { et al., 2017), } \\
\text { (Garvey et al., 2011) }\end{array}$ \\
\hline Sign luminance and retroreflectivity & $\begin{array}{c}\text { (Bullough, 2017), (Lundkvist, 2012), } \\
\text { (Garvey et al., 2011) }\end{array}$ \\
\hline Size of the sign & (Garvey et al., 2011), (Carlson et al., 2017) \\
\hline Shape of the sign & (Bullough, 2017), (Garvey et al., 2011) \\
\hline Colours of the sign & (Carlson et al., 2017), (Garvey et al., 2011), \\
(Bullough, 2017)
\end{tabular}

Furthermore, the effect of ambient illumination level (night or daylight) and street lighting have a big effect on the detectability (Garvey et al., 2011), (Bullough, 2017). In nighttime and on roads without public lighting, the retroreflective sheeting is important for improving detectability (Lundkvist, 2012). Among the photometric properties of the sign most related to detectability is the sign luminance and retroreflectivity (Bullough, 2017), (Lundkvist, 2012), (Owens et al., 2007), (Carlson et al., 2017), (Garvey et al., 2011).

Another factor that has negative effect on the detectability of road traffic signs and may lead to fatal nighttime crashes is the aging of the drivers (Carlson et al., 2017), (Owens et al., 2007). For older driver when the illumination reduces the average speed and detectability of road traffic signs reduce. This low detectability is found to be related to the reduction in driver's vision with aging (Owens et al., 2007). Table 1 summarizes the literature studying the factors affecting detectability. 


\subsection{Legibility}

Legibility is defined as the ability to read and process the information. Road traffic sign legibility depends on how easy the driver can read the text or symbols on the sign. In the literature, there were many studies have studied the legibility of road traffic signs and the factors that influence the reader's ability to process the information.

Among these factors is the amount of information on the sign and the size of the sign itself which have a big influences on the legibility (Bullough, 2017). For example the legibility can be improved by using graphical symbols and using alphanumeric characters has lower effect on the legibility (Bullough, 2017).

Other factors affecting the legibility are the design of the sign, such as sign shape and colour, and message design factors. Message design factors, such as font type, text size, letter height and letter spacing, are important to maximize the potential for a driver to read the sign within the road environment and increase the legibility of the sign (Funkhouser et al., 2008), (Bullough, 2017), (Garvey et al., 2011), (Lundkvist, 2012).

Moreover, sign luminance and retroreflectivity has a big impact on the legibility (Owens et al., 2007), (Schieber et al., 2004), (Bullough, 2017), (Lundkvist, 2012), (Garvey et al., 2011), (Kosmas et al., 2018). Generally speaking, increasing the luminance or brightness of a sign would increase its detectability but excessive brightness can lead to irradiation of the characters and symbols on the sign, reducing the legibility (Bullough, 2017).

Several factors found to systematically influence sign legibility distance were driving environment, ambient illumination level, street lighting and complex background visual clutter (Schieber et al., 2004), (Carlson et al., 2017), (Garvey et al., 2011), (Bullough, 2017).

The driver's skill and familiarity with road traffic signs in general, and in some cases, their knowledge of the selected road names have a significant effect on legibility distance (Funkhouser et al., 2008).

Another important factor is viewing geometry and location of a sign have also an influence on the degree to where it can be easily read (Garvey et al., 2011), (Kosmas et al., 2018), (Bullough, 2017).

Finally, it is important to mention that some studies failed to find a significant effect of certain factors on the legibility of the road traffic sign such as certain sign colour (Funkhouser et al., 2008) and driver's age (Schieber et al., 2004). For example, in one study the green and purple colours performed equivalently in terms of legibility distances during daytime and nighttime (Funkhouser et al., 2008). Table 2 summarizes the factors affecting the detectability. 
Table 2

Factors Affecting the Legibility

\begin{tabular}{|c|c|}
\hline Factor & Study \\
\hline Shape of the sign & (Bullough, 2017) \\
\hline Size of the sign & (Bullough, 2017) \\
\hline Sign luminance and retroreflectivity & $\begin{array}{c}\text { (Owens et al., 2007), (Schieber et al., 2004), } \\
\text { (Bullough, 2017), (Lundkvist, 2012), } \\
\text { (Garvey et al., 2011), (Kosmas et al., 2018) }\end{array}$ \\
\hline $\begin{array}{c}\text { Driving environment } \\
\text { High speed rural road/low speed suburban }\end{array}$ & (Schieber et al., 2004) \\
\hline Ambient illumination level and street lighting & $\begin{array}{c}\text { (Schieber et al., 2004), (Carlson et al., 2017), } \\
\text { (Garvey et al., 2011), (Bullough, 2017) }\end{array}$ \\
\hline Complex background visual clutter & (Schieber et al., 2004), (Bullough, 2017) \\
\hline Font type, text size, letter height, letter spacing & $\begin{array}{c}\text { (Funkhouser et al., 2008), (Bullough, 2017), } \\
\text { (Garvey et al., 2011) }\end{array}$ \\
\hline Colours of the sign & $\begin{array}{c}\text { (Bullough, 2017), (Lundkvist, 2012), } \\
\text { (Garvey et al., 2011) }\end{array}$ \\
\hline Driver's skill & (Funkhouser et al., 2008) \\
\hline Use of graphical symbols & (Bullough, 2017) \\
\hline Location of the sign & $\begin{array}{c}\text { (Garvey et al., 2011), (Kosmas et al., 2018), } \\
\text { (Bullough, 2017) }\end{array}$ \\
\hline Viewing geometry & (Bullough, 2017) \\
\hline
\end{tabular}

\section{Retroreflectivity}

Among the important ways to improve nighttime visibility is using the retroreflective sheeting for the road traffic signs. Retroreflective sheeting materials are used to support nighttime legibility of road traffic signs. The purpose of retroreflective sheeting is to reflect the light of the vehicles headlights towards the driver.

Retroreflecting sheeting is a material that has a thin continuous layer of small retroreflective elements that reflects light to its source (Pościk et al., 2019). It has been used for road traffic signs for more than 80 years and is still a key part of the road safety infrastructure on the roads nowadays (Berces et al., 2012). Different types of retroreflective sheeting reflect the light in different ways and in a different intensity depending on the material, they made of. There are many types of retroreflective sheeting materials available in the market today; therefore, choosing the suitable and effective type to be used for the road traffic signs is a challenge.

Retroreflectivity is the ability of a surface or material to reflect the light back to its source. Regarding road traffic signs, retroreflection represented by the coefficient of retroreflection, known as $R_{A}$ (its unit is candle/lux $/ \mathrm{m}^{2}$ ) which can be given by Eq. 1 .

$R_{A}=\frac{L}{E} \ldots$

Where:

$R_{A}$ - coefficient of retroreflection, $\mathrm{cd} / \mathrm{lux} / \mathrm{m}^{2}$;

$L$ - Luminous intensity, $\mathrm{cd} / \mathrm{m}^{2}$;

E - Illuminance, lux.

The luminance can easily be defined as the amount of light returned from the sign's surface to the human eyes that makes the sign appear bright. While the illuminance is the amount of light, subjected and spread on the road traffic sign, as shown in Figure 2. 


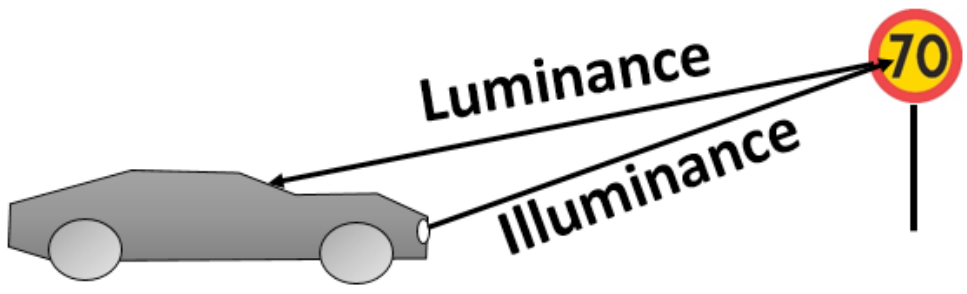

Fig. 2.

Illustration of the Retroreflectivity

Source: Generated by the authors

From Eq. 1, the amount of retroreflected light (luminance) of the road traffic sign depends on the illuminated light and the type of retroreflective sheeting materials. The luminance can be increased by using a material with high reflectivety. However, a very high retroreflectivity can cause negative effect by glaring the drivers' eyes. Choosing a retroreflective sheeting material with a proper reflective level for the road traffic sign can reduce such effect.

The luminance of the retroreflective sheeting materials depends on the type of material, the technology used in the production, ambient conditions, observation and illumination angles and the properties of the incident light (Junior et al., 2018), see Table 3.

\section{Table 3}

Factors Affecting the Luminance

\begin{tabular}{|c|c|}
\hline Factor & Study \\
\hline $\begin{array}{c}\text { Type of retroreflective sheeting material } \\
\text { (reflective layer technology, substrate type, and colour) }\end{array}$ & (Junior et al., 2018) \\
\hline Ambient illumination level and street lighting & (Junior et al., 2018) \\
\hline The angle of illumination by vehicle headlights & (Junior et al., 2018) \\
\hline
\end{tabular}

Since the first retroreflective sheeting was used for road traffic signs in 1937, the researchers began to study and develop these retroreflective sheeting materials (Khrapova, 2019). A summary of the factors affecting retroreflectivity is presented in Table 4.

Many researchers explored the impact of different factors on retroreflective properties of signs, see Table 4. Certain factors such as weather conditions attracted more attention (Khrapova, 2019), (Junior et al., 2018), (Carlson et al., 2017), (Kirk et al., 2001) while only few researchers studied the impact of dew and frost on the retroreflectivity. Furthermore, factors such as the temperature during measuring the retroreflectivity of in-service signs were ignored (Khrapova, 2019). 
There are other factors affect the retroreflectivity such as the ambient conditions, the angle of illumination by vehicle headlights, and the type of reflective sheeting material (reflective layer technology) (Junior et al., 2018). The type and colour of the retroreflective sheeting have a significant influence on the degree of degradation of the retroreflective values under dew and frost conditions (Khrapova, 2019). The colour of the light and the sign is also of the essence because it affects the photometric properties (Junior et al., 2018). In addition, the reflection coefficient depends on the surface of the retroreflective sheeting (Junior et al., 2018).

Table 4

Factors Affecting the Retroreflectivity

\begin{tabular}{|c|c|}
\hline Factor & Study \\
\hline $\begin{array}{l}\text { Weather conditions such as dirtiness precipitation, drizzle, dew and } \\
\text { hoarfrost }\end{array}$ & $\begin{array}{l}\text { (Khrapova, 2019), (Junior et al., 2018), } \\
\text { (Carlson et al., 2017), (Kirk et al., 2001) }\end{array}$ \\
\hline Colour of light and road traffic sign & (Junior et al., 2018) \\
\hline $\begin{array}{l}\text { Ambient conditions including surrounding light, temperature, dust and } \\
\text { moisture }\end{array}$ & (Junior et al., 2018) \\
\hline Angle of illumination by vehicle headlights & (Junior et al., 2018) \\
\hline $\begin{array}{l}\text { Type of reflective sheeting material } \\
\text { (reflective layer technology, substrate type, and colour) }\end{array}$ & (Junior et al., 2018), (Khrapova, 2019) \\
\hline Surface of the retroreflective sheeting material & (Junior et al., 2018) \\
\hline
\end{tabular}

A recent study (Khrapova, 2019), found that the majority of the studies did not provide data about temperature and air relative humidity and did not investigate the effect of weather conditions on the retroreflectivity of the road traffic signs. This study has also found that weather conditions such as rain, drizzle, fog, dew, and hoarfrost have a big effect on the visibility of the road traffic signs. Furthermore, the same study found that the presence of any type of precipitation on the surfaces of signs, such as dirtiness and frost, significantly impairs its retroreflective properties.

Many studies did not found any relationship between weather conditions and the retroreflectivity (Khrapova, 2019), (Junior et al., 2018), (Carlson et al., 2017), (Kirk et al., 2001). For example changing temperature or humidity has no connection with the retroreflectivity especially for sheeting with a high level of retroreflection (Khrapova, 2019). Even the relationship between the level of retroreflectivity and age of the sign could not be approved, especially with in the first twelve-years (Kirk et al., 2001).

\section{Discussion}

The factors that identified through this review and found to influence the visibility are summarized in Table 5. 


\section{Table 5}

Factors Affecting the Visibility of Road Traffic Signs

\begin{tabular}{|c|c|c|c|c|}
\hline $\begin{array}{l}\text { Human } \\
\text { Factors }\end{array}$ & Sign Factors & $\begin{array}{l}\text { Vehicle } \\
\text { Factors }\end{array}$ & Environmental Factors & $\begin{array}{c}\text { Road Design } \\
\text { Factors }\end{array}$ \\
\hline $\begin{array}{c}\text { Age } \\
\text { of the } \\
\text { Driver }\end{array}$ & $\begin{array}{l}\text { Sign retroreflectivity and type of } \\
\text { retroreflective sheeting material: } \\
\text { - } \quad \text { reflective layer } \\
\text { - } \quad \text { technology } \\
\text { - } \quad \text { substrate type } \\
\text { - } \quad \text { surface of the material } \\
\text { - } \\
\text { colour }\end{array}$ & $\begin{array}{l}\text { The angle of } \\
\text { illumination } \\
\text { by vehicle } \\
\text { headlights }\end{array}$ & \begin{tabular}{ll}
\multicolumn{2}{l}{ Ambient conditions: } \\
- $\quad$ illumination level \\
- & surrounding light \\
- & street lighting
\end{tabular} & $\begin{array}{c}\text { Driving } \\
\text { environment } \\
\text { High speed rural } \\
\text { road/low speed } \\
\text { suburban }\end{array}$ \\
\hline \multirow[t]{6}{*}{$\begin{array}{l}\text { Driver's } \\
\text { Skill }\end{array}$} & $\begin{array}{ll}\text { Text: } \\
\text { - } & \text { Font type, } \\
\text { - } & \text { text size, } \\
\text { - } & \text { letter height, } \\
\text { - } & \text { letter spacing }\end{array}$ & $\begin{array}{l}\text { Colour of } \\
\text { headlights }\end{array}$ & 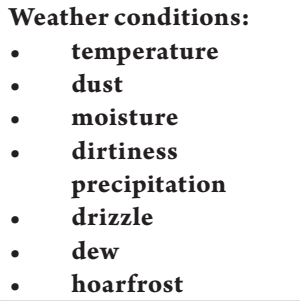 & \\
\hline & $\begin{array}{ll}\text { Sign: } \\
\text { - } & \text { Location } \\
\text { - } & \text { size } \\
\text { - } & \text { shape } \\
\text { - } & \text { colour } \\
\end{array}$ & & $\begin{array}{l}\text { Visual Complexity levels } \\
\text { and complex background }\end{array}$ & \\
\hline & Visual clutter & & & \\
\hline & Adding border around the sign & & & \\
\hline & Use of graphical symbols & & & \\
\hline & Viewing geometry & & & \\
\hline
\end{tabular}

The factors that influence the visibility can be divided into five groups:

1. Human factors;

2. Factors concerning sign;

3. Factors concerning vehicle;

4. Environmental factors;

5. Road design factors.

The factors written in bold text in Table 5 are those that affect the retroreflection and have been included in the previous studies, while the other factors have unknown effects on the retroreflection. Human and road factors were not studied as affecting factors according to the literature review while factors concerning sign, vehicle or environmental factors were found to be effective on the retroreflection. The location, size, shape, colour of the sign, and type of retroreflective sheeting material have an impact on both, the detectability, and the legibility. The retroreflectivity of the road traffic sign have a big effect on the visibility.

\subsection{Does the Retroreflectivity Affect the Visibility of the Road Traffic Sign?}

The studies included in the current review concentrated on the effect of retroreflectivity and luminance on the detectability and legibility of the road traffic signs. These studies gave clear evidence that the nighttime visibility improves by using the adequate level of retroreflectivity. The reason for this is that the luminance from the retroreflective signs improves the detectability and legibility of the road traffic signs. 


\subsection{Factors Affecting the Visibility of the Road Traffic Sign}

Most of the studies reviewed in this paper studied sign factor (shape, size, colours etc.) and found that this factor is the most related to the visibility compared with the other factors.

The vehicle headlights, ambient condition, and the type of retroreflection sheeting material affect the luminance of the road traffic signs. The vehicle factors (headlights colour and angle of illumination), environmental factors (weather and ambient conditions) and sign factors (type and colour of retroreflective sheeting material) found to be essential on the retroreflectivity.

The exciting literature cover a wide range of research related to the factors affecting visibility while only a few references founded on the factors affecting retroreflectivity and luminance.

\subsection{Missing Evidence about Some Factors that can Affect the Visibility of the Road Traffic Sign}

Many studies found that the colours of the road traffic signs affect the visibility including legibility but, in some cases, when purple is used instead of green backgrounds, the colours have no significant effect on the legibility.

According to many studies, the age of the driver affects the legibility of the road traffic signs but a surprising result from one study was the complete lack of any statistically significant differences in sign legibility based upon driver age.
The weather conditions affect the retreflection but the retroreflection does not always depend on the changes in temperature and humidity especially for sheeting with a high level of retroreflection (Khrapova, 2019). Furthermore, the retroreflectivity of road traffic signs do not vary much due to weather conditions with age especially within the first twelve-years of the sign age (Kirk et al., 2001). This can be motivated because of the twelve years span are not long enough to detect weathering effects.

\subsection{Factors not Covered by the Research Studies}

Based on the results of this literature review, there are some factors which have unknown effects on the visibility of the road traffic signs and need therefore further investigation. At the same time, the combinations of two or more factors was not investigated either.

Human Factors/Detectability and Legibility

Age and skills of the drivers have effects on the detectability and legibility of the road traffic signs according to three studies. The effect of other human factors such as visual characteristics, health condition, tiredness, medicine, stress, and mental load, need to be studied.

\section{Vehicle and Road Design Factors/Detectability and Legibility}

There is no evidence about two factors, road design and vehicle factors, which can influence the detectability and legibility of the road traffic signs. 


\section{Human and Road Factors/ Retroreflectivity}

This review demonstrates the need to conduct research on the effect of human and road factors on the retroreflectivity. The hypotheses that Road factors (such as road design and alignment) have a big effect on the driving geometries and therefore can affect the retroreflectivity need to be tested.

There is even a general lack of prior studies on the factors affecting the retroreflectivity and most of the studies concentrate on the factors affecting detectability and legibility.

\section{Conclusion}

In the recent years, many studies have addressed the effect of the retroreflectivity and luminance on the night-time visibility of road traffic signs. This paper gathers the existing knowledge from previous work about night-time visibility of the retroreflective road traffic signs and collects the factors affecting visibility. The results from this paper allowed us to establish the importance of the retroreflectivity and luminance on improving the detectability and legibility of the road traffic signs. In addition to that, many studies gave clear evidence that the night-time visibility improves by using the adequate level of retroreflectivity.

The knowledge produced by this paper is expected to provide a guide for the road authorities when it comes to the importance of using retroreflective sheeting material to improve night-time visibility and what factors affecting the performance of this material.

An important contribution of this paper is in gathering the results from previous studies to summaries the factors affecting nighttime visibility of the retroreflective traffic road signs.

The vehicle headlights, ambient condition, and the type of retroreflection material were found to affect the luminance of the road traffic signs. The retroreflectivity depends on vehicle factors (headlights colour and angle of illumination), environmental factors (weather and ambient conditions) and sign factors (type and colour of retroreflective sheeting material). Furthermore, the results from previous work point to the fact that the weather conditions affect the retreflection but the retroreflection does not always depend on the changes in temperature and humidity especially for sheeting with a high level of retroreflection. It was also found that the retroreflectivity do not vary much within the first twelve-year of the sign age. The sign factors (shape, size, colours etc.) were the most related to the visibility compared with the other factors.

Most of the literatures cover the factors affecting visibility (detectability and legibility) while only a few references found on the factors affecting retroreflectivity and luminance. This result gives therefore a recommendation for future studies to investigate the factors affecting retroreflectivity. The effect of human and road factors on the retroreflectivity has not been investigated and thus the hypotheses that these factors have a big effect on the retroreflectivity need to be tested.

Age and skills of the drivers have effects on the visibility of the road traffic signs but the effect of other human factors such as visual characteristics, health condition, tiredness, medicine, stress, and mental load need to be studied. Furthermore, there is no evidence 
about the effect of two factors, road design and vehicle factors, which can influence the visibility of the road traffic signs. For this reason, the understandings of the effect of road design, human and vehicle factors, and the interactions between these factors on the retroreflectivity need to be increased.

\section{References}

Allen, T.; Arthur, L. 1956. Sign brightness and legibility, Highway Research Board Bulletin 127: 1-14.

Berces, A.; Robertson, S. 2012. Keeping People Safer Through Better Visibility Advances in Retroreflective Technologies for Road Signage, Pavement Markings and Vehicle Visibility Delivering Safer Roads. In Australasian Road Safety Research, Policing and Education Conference, Wellington, New Zealand. 12 p.

Bullough, J. 2017. Factors Affecting Sign Visibility, Conspicuity, and Legibility: Review and Annotated Bibliography, Interdisciplinary Journal of Signage and Wayfinding 1(2): 2-25.

Carlson, P. 2001. Evaluation of Clearview Alphabet with Microprismatic Retroreflective Sheetings. Texas Department of Transportation and the U.S. Department of Transportation, Federal Highway Administration. $88 \mathrm{p}$.

Carlson, P.; Brimley, B.; Chrysler, S.; Gibbons, R. Terry, T. 2017. Recommended Guidelines for Nighttime Overhead Sign Visibility, Transportation Research Record 2617(1): 27-34.

Chrysler, S.; Carlson, P.J.; Hawkins, G. 2002. Nighttime Legibility of Ground-Mounted Traffic Signs as a Function of Font Color and Retroreflective Sheeting Type. Texas Transportation Institute. $76 \mathrm{p}$.

European Committee for Standardization. 2007. EN 12899-1 Fixed, vertical road traffic signs - Part 1: Fixed signs. 57p.
Funkhouser, D.; Chrysler, S.; Nelson, A.; Park, E. 2008. Traffic Sign Legibility for Different Sign Background Colours: Results of an Open Road Study at Freeway Speeds, Human Factors and Ergonomics Society Annual Meeting Proceedings 52(23): 1855-1859.

Garvey, M.; Kuhn, B. 2011. Handbook of Transportation Engineering, Highway Sign Visibility. Mc Graw-Hill Handbooks. Ch. 7.1-7.15.

Junior, O.S.; Silva, E.S.; Barros, K.N. 2018. New method for characterization of retroreflective materials, JPhCS 975(1): 012033.

Khrapova, M. 2019. Determining the Influence of Factors on Retroreflective Properties of Traffic Signs, Agronomy Research 17(S1): 1041-1052.

Kirk, A.; Hunt, A.; Brooks, E. 2001. Factors Affecting Sign Retroreflectivity. No. OR-RD-01-09. Oregon Department of Transportation. Research Group. 29 p.

Kosmas, K.; Kobbert, J.; Khanh, T. 2018. Optimal Traffic Sign Luminance with Glare-free High Beam, ATZ Worldwide 120(9): 76-79.

Lundkvist, S. 2012. Performance assessment of road equipment State of the art. Linköping, Statens väg- och transportforskningsinstitut, $27 \mathrm{p}$.

Madleňák, R.; Hoštáková, D.; Madleňáková, L.; Drozdziel, P.; Török, A. 2018. The Analysis of the Traffic Signs Visibility During Night Driving, Advances in Science and Technology Research Journal 12(2): 71-76.

Owens, D.; Wood, J.; Owens, J. 2007. Effects of Age and Illumination on Night Driving: A Road Test, Human Factors 49(6): 1115-1131.

Pościk, A.; Szkudlarek, J.; Owczarek, G. 2019. Photometric Properties of Retroreflective Materials in Dependence on their Structure and Angle of Illumination, Fibres \& Textiles in Eastern Europe 3(135): 58-64. 
Šarić, Ž.; Xu, X.; Duan, L.; Babić, D. 2018. Identifying the Safety Factors over Traffic Signs in State Roads using a Panel Quantile Regression Approach, Traffic Injury Prevention 19(6): 607-614.

Schieber, F.; Burns, D.; Myers, J.; Willan, N.; Gilland, J. 2004. Driver Eye Fixation and Reading Patterns while using Highway Signs under Dynamic Nighttime Driving Conditions: Effects of Age, Sign Luminance and Environmental Demand. In TRB 2004 Annual Meeting, $26 \mathrm{p}$.

Sivak, M.; Olson, P.; Pastalan L. 1979. Effect of Driver's Age on Nighttime Legibility of Highway Signs. Highway Safety Research Institute, Institute of Gerontology, University of Michigan. 